\title{
Continuous Process Improvement (CPI) in Pakistani Banking Sector for Improving Overall Performance
}

\section{Saeed MS $^{1 *}$ and Nasar $\mathrm{A}^{2}$}

${ }^{1}$ Business Management, Glasgow Caledonian University, Glasgow Business School, Glasgow, UK

${ }^{2}$ Government Model Degree College (for Boys), Lahore, Pakistan

\begin{abstract}
The purpose of this paper is to study the implementation of CPI in the bank, and to analyse the merits and its effect on the competitiveness of banking in order to develop PBS (Processing Bank System). The theoretical structure, features and the functions of the CPI theory has progressed after the thorough investigation. Then a hybrid theoretical model of CPI-PBS was developed. The PBS dynamic optimisation system has been developed through the implementation of Lean Six Sigma (LSS) and then we put up an empirical example to indicate the performance of CPI model. Finally the research reached to the conclusions after the thorough analysis. Firstly, the implementation of CPI theory has a healthy impact to service industries, however, the appositeness and conceivability should be taken into account. Secondly, the amelioration of process in commercial banks is an effective, constant progressing process and we can achieve a good synergism effect that the imperative amalgamation of CPI theory and PBS thinking. Finally, it should be realised that the LSS alone was not sufficient and PBS should be considered. The idea and model of the CPI with the methodology of LSS should be combined. Then we identify the issues and steps of the implementation of CPI to management banks.
\end{abstract}

Keywords: Continuous process improvement; Banking sector; Performance; Department of defense

\section{Introduction}

The international economic system moved to integration. Pakistani integration due to its interest and drift has entered into global market. The period of post economic crisis rests on the global economy and high tech as essential elements. The banking sector was the victim as a result of the US subprime mortgage crisis and this crisis alert the banking sector. At that time it was an inexorable choice to set up banking management model globally and persist to build up the core competitiveness. Processing Bank System (PBS) is an extremely used model of management for many banks with an international level. The banking industry of Pakistan made some progress when they started to research the framework of PBS since 2006. The development of PBS was a serious issue in order to promote it in an effective manner from the aspects of strategic implementation and certain techniques.

The commercial banks need CPI (Continuous Process Improvement) to accommodate to the present financial promotion and the global trend for increasing their core competitiveness for the sake of understanding PBS productively. As its core management to develop PBS should remodel moderately to the management strategy specifically strategic core business, the pursuit of efficiency and organizational change. The theory of CPI is an approach that guided the organization to understand and ameliorate the process effectively. It is a theory that is customer oriented and it implemented all types of tools to understand the systematic management. Thus the requirement of CPI is not only the changes in the external environment, but also from their own internal requirements for commercial banks.

CPI has been implemented in managing all kinds of procedures to administer the frequent transformation in our worldwide surroundings. This is also a verified proficient method in the Department of Defense (DOD) [1]. But after investigating the functions of CPI theory, we discovered that it hardly ever talked about business accomplishment or achievement from the perspective of the service industry, particularly in banking services, which is the most serious subject matter in service operations and the centre of attention of a majority of the study is typically on the military issues or medical concerns. Currently, service operations encompass more than $40 \%$ of the GDP in Pakistan and are hastily rising globally, and banking services is the utmost grave issue in the service industry. This research filled these spaces.

Based on the above research, this investigation examined Pakistani commercial banks, i.e. how to construct PBS in outlook of CPI and by structured approach.

The objectives of this research are: we look at the CPI theory, Processing Bank System (PBS) theory and Lean Six Sigma (LSS) theory. After that we explain the similarities and dissimilarities between the theories of CPI and LSS and the relationship between them. The development of commercial banks PBS on national and international level has been explored in this paper. The CPI theoretical has been investigated and improved from the theoretical system, core ideas, implementation tools and the techniques. The theory of the CPI and PBS thinking has been integrated in order to present a CPI-PBS hybrid deployment model in this paper. This conceptual model uses the techniques of LSS as the major tool for implementing CPI theory. The Key Performance Indicator (KPI) has been used between the macro and micro level in the CPI-PBS hybrid deployment model as a control node. After the careful analysis, the study applies a process improvement model that is appropriate to the commercial banking system.

The objective of commercial banks can be achieved at the end. The study explained the PBS framework from the two stages of strategic

*Corresponding author: Muhammad Sajid Saeed, $\mathrm{PhD}$ in Business Management, Glasgow Caledonian University, Glasgow Business School, Glasgow, Cowcaddens Rd, Lanarkshire G4 OBA, Scotland, UK, Tel: +441413313000; E-mail: msaeed14@caledonian.ac.uk

Received July 20, 2016; Accepted September 22, 2016; Published September 30, 2016

Citation: Saeed MS, Nasar A (2016) Continuous Process Improvement (CPI) in Pakistani Banking Sector for Improving Overall Performance. J Bus Fin Aff 5: 210 doi: 10.4172/2167-0234.1000210

Copyright: @ 2016 Saeed MS, et al. This is an open-access article distributed under the terms of the Creative Commons Attribution License, which permits unrestricted use, distribution, and reproduction in any medium, provided the original author and source are credited. 
deployment and financial practices which proved the feasibility and acceptance by the case from bank C. Then it explored various departments' operations so as to strengthen them and to increase the internal operation control of the banking sector. It examined the feasibility and application of the CPI implementation in order to develop PBS. It identifies the issues of the CPI application to management banks. The rest of the part of the paper is divided as follows. Section 2 includes the literature review; section 3 describes the development of the PBS model; section 4 discusses the case study; conclusion, recommendations has been discussed in the last section.

\section{Literature Review}

\section{CPI and applications}

Quality is a continuous quest and CPI is a continuous effort to eradicate and identify the roots of the issues [2]. CPI system is a technique that needs the integration of all the development activities to achieve the operational objectives. CPI system is a customer oriented learning that guides the organization innovation of thinking and process development with CPI tools to comprehend all types of systematic management for instance revolution thinking, flowcharts, process diagrams, knowledge discovery tools and much more $[3,4]$.

CPI is a strategic process to develop a feasible improvement trend in the productivity, feature, decision making process and revolution process. It is an approach to expand the benefits and revolution performance, cost management, product discrimination and improvement in the resource [5]. We explore to learn the things what makes them happen and then utilize this knowledge to lessen the changes, eliminate those activities that are worthless to the organization and improve the customer satisfaction when we are dealing with the process improvement [6]. The main objective of CPI is the selfexamination of processes. That is a method of feedback [2]. The motive of CPI theory is to identify, lessen and eradicate the processes of poor quality to make it more efficient.

The focus of CPI is additional and continual steps in order to stay away from the abrupt changes. It is a form of advancement [3]. The components above are the most strategically components of CPI [7]. The more strategic components involve decisions that how to enhance the delivery process value and how much flexibility is important in the process to meet the varying needs [8]. Some analysers express CPI as a meta- process for some systems of management for instance Project Management, Quality Management and Business Process Management [9]. Wilson and Dobson saw it as a system part through which feedback from both the customer and process were estimated against organizational goals [10].

The management process does not necessarily mean that it needs to be implemented by management solely but it makes decisions about the design and implementation of the delivery process [9]. There are many techniques to comprehend CPI [2]. The main focus is on the small improvements rather than extensive change and makes an effort to remove the worthless activities. CPI is significant for organization because Pareto's Principle (the $80 / 20$ rule) applies. It is said that $80 \%$ of all problems report the processes, whereas the remaining $20 \%$ report people [11].

The main focus on CPI is on the four key elements that need a comprehension and support to promote the current CPI strategies for the advancement of greater enterprise level. The first key element is broad-based organized CPI implementation method that emphasize mainly on why a safe plan is required and how to implement the best result. The second key element is an emphasis on the implementation of CPI confined to a structure of objectives that are oriented to outcome based metric. The third key element laid stress on the combination and management of CPI project. The fourth and final key element decides how good the organisations and projects are improving with the training, certification and techniques of CPI. Continuous improvement is a successful achievement to improve the processes, product and services. These achievements can pursue step-by-step advancement over time or breakthrough advancement altogether [12]. There are plenty of examples for the implementation of CPI techniques into lower costs, reduced cycle times and productivity gains [4,9]. CPI is an approach that has been acquired successfully in management processes in order to manage abrupt changes in the environment globally. CPI consists of the implementation of a diverse range of tools for instance, Six Sigma, Lean and Theory of Constraints (TOC) in Department Of Defence (DoD).

In Department Of Defence (DoD) CPI is a strategic methodology for the advancement in the field of accuracy, quality, efficiency, cycle times, less consumption of resource and cycle times [1]. The things done within the Department Of Defence (DoD) are directed by the process. They have the process of acquisition for creating and obtaining their defence system, processes for maintaining the tools, processes for presenting travel claims and others. As a result, the productiveness, effectiveness and quality of our work are operated by the processes we utilize to do our work [13]. CPI presents techniques, tool and ideology that can be utilized to advance the system we work with. It is implemented on a continuous basis, which results in the efficacy and effectiveness. DOD is now acquiring these implementations and gripping the knowledge obtained from these unique pockets of $\mathrm{CPI}$ success [14]. Consequently, the strategic approach for the advancement in the field of accuracy, quality, efficiency, cycle times, less consumption of resources and cycle times has been achieved [1].

The CPI has been verified as an important tool for the advancement of the achieving efficiency within DOD. For instance, the Air Force implemented CPI to improve the management process concerning medical and lessens the flow time on giving authorizations from 97 hours to 1 hour. The Army utilized a Lean approach to enlarge the mean time between overhaul for helicopter engines by 300\%. Within two years the Navy lessen the cycle time for F404 jet engines by $78 \%$. Similarly the Marine Corps implemented tools of TOC to lessen the repair cycle time for $\mathrm{CH}-46$ helicopters by $40 \%$. These favourable outcomes and others similar to them exhibit CPI's ability to implement outstanding, compatible practices to perform a diverse range of operational requirements.

These good practices decide for huge improvement on the business level. CPI aims at building each process more and more efficient. The theory named Kaizen put emphasis on the increasing effect of improvements on small levels. This theory Kaizen operated on the unsolicited and tangled change [3]. Nobody realizes an effective, management or running department like those operating in it each day. Some published reports specified this additional approach can yield in $100 \%$ efficiency across the duration of $12-18$ months $[8,12]$. But the improvement will differ from organization to organization stated by how inefficacious an organization was at the time when reestablishment start. Because of the incremental nature of the variations the investments in CPI are generally small.

\section{Continuous process improvement (CPI) and processing bank system (PBS)}

The requirement of CPI is not only from the external variation 
environment, but also from their internal requirements for the commercial banks. The banking sector experienced the pressure of the American sub-prime mortgage crisis. The extreme ferocious competition has been experienced by the Pakistani commercial banks in domestic and foreign markets. The commercial bank experienced the constant ferocious competition in the market and also in the customer market maturing as a service industry. In general the demand for the products and services has been tremendously increasing. In order to develop PBS, the core of management should slowly change into the strategy oriented management that is strategic core business, seeking of effectiveness and quality and the organizational change. CPI theory is an ideology and a technique that manages the organization to comprehend and improve the process effectively. Therefore, we need CPI to observe the existing financial deepening and the global trend to put emphasis on customer, to increase their core competitiveness, to answer seriously to the market competition idea in order to realize PBS [15].

The Processing Bank System (PBS) indicates a commercial bank management model which is extremely used as a management model for many international banks. This management model is customer and market oriented that mainly focuses on the key rules of business within the marketing, accounting and management system. According to the definition of Deloitte's, PBS is the services of banks from work, uncertainty, rules and quality to apply the five principles to front, central and background processes. Furthermore, the bank cannot be too hasty in avoiding risks, according to these five principles. The working of PBS puts emphasis on the vertical management on area of distinct business and it also emphasizes on dealing with the business of monitoring, accounting, billing and customer oriented management and a great number of middle and background business.

The quality of PBS is to adapt its conventional operating methodology and to create an up to date banking model that put emphasis on customer with the support of IT technology, with the qualities to organizational modernization and process advancement, modification and designing, with resource integration in all fields. PBS incorporates the flexible capacity of the latest bank and competitiveness by keeping balance, understandable duties and rights, team harmony to become accustomed to the rapid revolutionizing market.

In order to build a PBS effectively than we have to indicate the Business Process Reengineer (PBR). The simple definition of PBR mentioned in the Davenport introducing book-Reengineering the Corporation: A definite Business Evolution [13]. They explained BPR that it is a continual methodology that demands intense dedication and creativity of the top management. This type of incremental alterations to create PBS comprised of four levels that is the identification of process, improvement, reengineering and homing.

\section{Lean six sigma (LSS) and processing bank system (PBS)}

Lean Six Sigma (LSS) is the ideal model that is the integration of six sigma theory and lean production theory. CPI which is implemented on DOD is built on three supportive, but different perspectives that is Lean, Sigma and TOC [1]. Lean Six Sigma has been extensively used and built in all kinds of management processes as an important tool of the CPI theory [16]. As we are familiar with the modification on a large scale, early adopters of Lean Six Sigma for accounting services for instance Merrill Lynch, Bank of America and Vanguard have broken the potential of this technique to build billions of dollars in reducing the cost of business and customer service rates which has been improved up to $25 \%$. This methodology of management has four important elements: 1 . Please greatly your customers with the quality and speed, 2. Improve processes consistently, 3. Cooperation for maximum gain, 4. build decisions on facts and data [17]. LSS combines Six Sigma and Lean manufacturing, gripping the benefits of the two models of management to build up for the shortage of single management model to gain " $1+1>2$ " team effort and acquire the top quality management effectiveness. LSS has put emphasis on the satisfaction of the customer and its working focus on systematized processes, lessen volatility to stabilize and enhance the interests of all as a management philosophy [18]. LSS focus on the Critical Success Factors (CSF) so as to put emphasis on the cultural development, process concentration, management support and select the right person, right method and tools. Then it becomes a strong supportive toll to the CPI theory.

LSS is an advance strategic methodology based process. The performance of the organization working depends on the performance of the core process. Banks apply considerable importance to the processes that is the financial sector building. But the concentration of the commercial bank management resides in the effective process management [18]. PBS is an efficient organization process with the management as a beginning point; for the present it means that its management of the system and the operating procedures will also be initiated from the process as a plan or outline for work [19]. Therefore LSS would be a powerful support to create PBS. All of the financial industry is intimately associated with the process. The bank of America implements the six sigma process firstly as the key management tool to bank services industry in order to research the evolution of PBS on national and international bank.

The business operations have a powerful consistency, repetition and comparatively more systematized business processes in the bank. These features are extremely worthy for the LSS thinking and perspective for improving the business processes. Nevertheless the evolution of information technology is a business. The equipment or computer cannot entirely substitute the service resources to give it to the customers. LSS builds decision by data, although the immense financial transaction data and extremely information oriented acquisition system to obtain problem solving data for creating eccentric conditions for "making decision by data" [20].

Unlike the typical sense of sequence, the greatest difference of PBS value sequence is that it is a process based on a closed loop. The value source that arrives from the group of customer value is not only the termination of the whole value chain. In fact, it is also the potential of some powers and associates which operates the entire bank operations from the bank evolution in the channel development. Therefore the model of the entire value chain of PBS can be concluded as: ACFC ("At Customer, for Customer"). At customer belongs to the viewpoint of the customer's status through its own products, marketing, maintenance and running of IT system, channel management et al. so the value of PBS arrives from the Voice of the Customer (VOC). It is a well said that who comprehends the customers will be victorious in the market [21].

\section{Developing PBS deployment framework}

Operations are seen in the circumstances of customer belief and needs, requirements of resource and technology and the operational environments. The fundamental ideas of CPI are set into use through a methodology of CPI deployment that should alter how we consider and think about work. It gives satisfaction to the customers that is value oriented, but not task oriented with the importance defined by the customer. The aim of PBS is to fulfil the requirements of customers and increase the core competence. In order to realize the core 
competitiveness, the Pakistani banks require CPI. The banking business operations have a strong consistency and repetition and comparatively more uniform transaction process. These features are best fitting for LSS thinking and methodology to comprehend improvement in business process $[15,18]$. The two processes, i.e., planning and implementation and each step in the CPI-PBS hybrid deployment model has been shown in the Figure 1. These two processes of planning and implementation are supportive. The outcomes from the implementation are sending back to the planning cycle like the implementation of CPI-BPS that is guided by the deployment planning (Figure 1).

\section{Step 1: Initial process}

The first process of the hybrid development model CPI-PBS is planning. The CPI deployment model is initiated with the evolution of CPI, innovation statement and is accompanied by a strategic approach on how to create the innovation a reality. The concentrated innovation, understandable vision and strategic oriented plan present the structure to acquire the goals of the organization. There are five factors that could help to comprehend them.

1. Innovation and developing orders that promote teamwork, inter departmental teamwork and adjustment between objectives and measures.

2. Emphasize on decreasing the limitations to acquire more suitable usage of resources and potential.

3. Maintain a speed of improving achievements.

4. Improved principle for the decision making and analysis.

5. Enlarging viewpoint on the complete value stream.

The target of CPI is a brief, explicit and quantitative explanation of the role of organization with the goals altogether. The mission of the $\mathrm{CPI}$ in a future sight is that it briefly explains how the organization will manage the business. It also shows a break between the existing and future state. The strategic approach gives the actions on a high level that can be taken over the time span of the plan to create the innovation a reality. The objective is to depict all inclusive and integrated road map for the organization that give strength to its objectives or aims for mission completion. The strategic approach must be an active contract

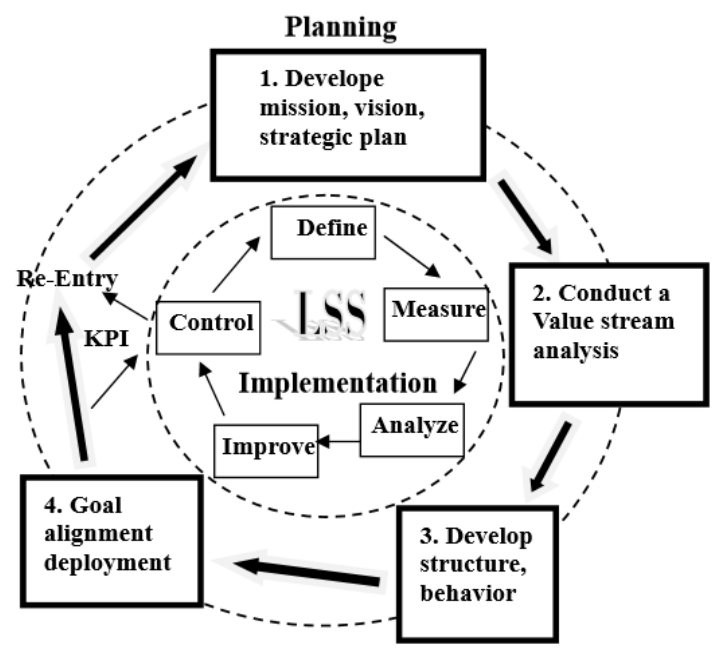

Figure 1: CPI-PBS hybrid framework. that explicitly focuses on the surroundings in which the operation of the organization takes place.

Adopting Lean philosophy tool the second level of the deployment model arises that account for the establishment of the value stream map and managing the analysis linked to it.

A value stream incorporates the overall planning, implementation, services and products that move on to a process in order to build up the customer value. Through vision, mission and strategic approach, the first goal is to orient the processes to support that direction. And the best method is a value stream mapping process that guides to demonstrate the opportunities for the improvement. Value stream mapping and analysis put emphasis on the customer value and it commonly comprised the existing state map development which explains the current process. It also discovers improvement chances and a future state map that illustrates the future process which are desired and the gap research analysis expose capable leverage points for the improvement in the process. The organizational value stream mapping activities usually comprised of the analysis and association of the two processes that is value added and non-value added. A value stream map holds all the activities that are needed to yield a service or a product to the customer and utilizing a value stream map to the initial document that how we perform our jobs currently and can point out those processes or actions that counts no value to the customers [22]. The analysis of value stream helps to teach the series of efforts we put in the addressing process ineffectiveness with efficient projects of CPI. At multiple levels, the value stream analysis is managed inside an enterprise and is normally achieved as a top down action.

The third stage of the deployment model is called as "develop structure and behaviour". This process makes an organizational structure and training certification program to make CPI successful within an organization [23]. The target completion on the basis of the cost wise and effectiveness successfully relies on the encouraging infrastructure development. The success of any strategy or a plan is totally relying upon the strong teamwork [24].

A CPI support team gives training of CPI and does smoothly the CPI management of initiatives, work team manages each step individually and peer should also be used to enhance the performance as desired conduct by the CPI committee. The champion expresses the main values and builds up the foremost expectations for the mission and innovation of an enterprise within this framework. The champion also requires to build an association with all the components of the enterprise concerning the CPI meaning and its goals. The champions must share through the organizational hurdles and trickle in covering these connections and make it continual for instance in the champion sponsored town hall meetings in General Electric. The leading committee is the main channel for the champions in order to keep up the CPI effort oriented to the expectations. The team of CPI also gives the technical skills and stable approach. This permits CPI to be a repeatable methodology that is established in the attitude and speech of the organization and eventually it becomes a defining part of its culture. The CPI working team acquires the peer groups input when desired and maintains alternatives for the improvements. Peer groups work inside and outside the functional areas to share skills, best applications and standard. The hierarchy is finished with the development of peer groups of CPI that gives moral support and share information outside the organization and explore methods to actively boost the outputs across many methodologies.

The fourth stage in the deployment of the CPI-PBS is the 
orientation and deployment of the goals. One of the main parts to move forward in an organization in a cooperative way is through the deployment and orientation of the objectives. The objectives should be developed for the support of an organization and be uniform with the high level commands objectives. There should be an unambiguous association between the objectives of the commands and reporting sub units. It is mandatory that the achievement of goals progress can be precisely considered and observable. The output should be the metrics and it is completely based on the tool for day to day operations and oriented with the objectives of organizations. These objectives need to be computed through the considerate developed metrics. These metrics will teach the working on daily basis, whereas an organization carries on its vision. There must be a straightforward, distinguishable and an easy going connection between every metrics and more than one objective. The efforts of CPI should be opted and executed with the goals of the organization and work hard to achieve the effective value stream.

\section{Re-entry and KPI}

The entire process should be reviewed at irregular intervals in order to check if the organization is moving forward toward the end state by the innovation and mission in the strategic plan. This needs to get back to the start and again visiting the steps of mission, innovation and strategic plan. Between the two levels of deployment model that is macro level and micro level the study used key performance indicators (KPI) as the control node. This process has been shown in the Figure 1 with the KPI.

Key performance indicators are essential as they estimate the process improvements in banks or organizations and can improve the efficiency and performance. These indicators are used to tell the execution of the organization strategic approach and KPI system is the notification for the organizational strategic approach and plan variations. All the steps should be visited again in the same way so as to make it sure that the organizations are moving forward in the right direction. This feedback performs to do some activities of planning as the continuous improvement process [1].

\section{Step 2: DMAIC process}

Implementation is the second process of the CPI-PBS hybrid deployment cycle. Once the basis of the CPI deployment model has been developed with the four planning activities then the implementation phase comes based on the LSS theory and it is comprised of five phases. The DMAIC project technique has five stages:

Define the problem: it mainly focuses on the goals of the project and customer voice.

Measure key aspects: it includes some features of the existing process and data being gathered.

Analyse the data: it is used to look into the cause and effect relationships. It also tells what the relationships are and an effort to make it sure that all the ingredients have been taken into account. It also explores the main causes of the flaws under proper analysis.

Improve or optimize the current process: it is based on the DOE (Design of Experiments) methodologies, analysis, mistake proofing and quality work to make a new, future state process (He et al.)

Control the future state process: this process ensures the variations before the result gets faulty. Control systems are executed for instance SPC (Statistical Process Control), visual work places and production boards so that the process is operated consistently.
For the implementation of the operational plan, terms need to be identified first and instructed in the techniques of CPI. Targeted processes are formed on utilizing the value stream maps by using the LSS techniques. With the implementation of LSS classic process DMAIC against the operational plan is controlled utilizing the formerly metrics. CPI is a strategic approach for acquiring the operational levels. It increases the existing execution by representing and uniform positive outcomes delivered by the staffs. Feedback through teams, committees, peers and CPI winners is used for improving the outcomes.

\section{Case Study}

The essential condition in this case is as follows: there areas even windows that are serviced by the Bank $\mathrm{C}$ staff, and the windows that are being utilizing are only three. However the customers hardly utilize ATM as long as the queue arrives in the windows that are serviced by the staff. The service time of twenty seven customers is shown in the Figure 2 and we can determine that the average service time to be 104 second. We research the data from the bank $C$ and reach to the conclusions as follows. The average arrival evaluates every customer that is 132 people per hour and present Poisson distribution. Similarly the average service rates for each window are about 35 people per hour and presents exponential distribution. On the whole there were three windows in service and fewer customers around 13:30 however the quantity adds up at a fast speed. At 13:30 roughly the window is added in which there are four windows service at that time. Approximately 14:10 another window is added again (Figure 2).

\section{Define}

Problem Description: The Bank $\mathrm{C}$ has a high rate of queue as it has an average service time of 104 second and also there is a great distance between the satisfaction and hope of the customers. The customer would move to another bank if the bank C didn't improve the effectiveness.

Aim Description: it improves the efficiency of service and increase the service amount to 60 persons per hour. A SIPOC diagram (a tool that is used to find and classify the process kinds to the suppliers, process, input, output or customers) have been drawn considering the service process and we can sketch the flow diagram for the service system of Bank $\mathrm{C}$ as shown in Figure 3.

\section{Measure}

In this phase of measuring, the timing of each level should be measured as well as we study our idea about the data and sample that has been gathered and measure the appraisal system data when required. We can reach to a conclusion that there is a straightforward correlation

\section{Distribution of Service Time}

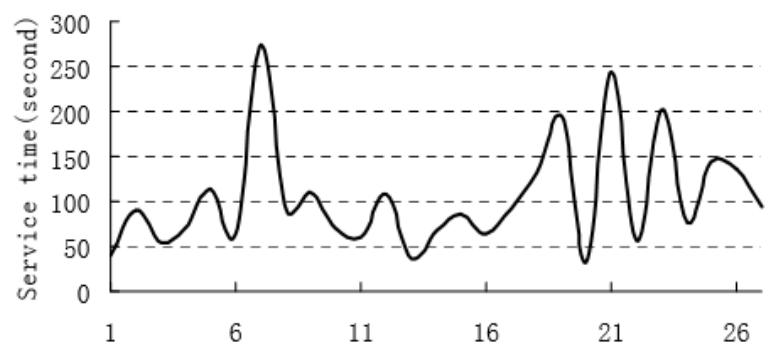

Figure 2: Service distribution time. 
between the issues occurring in the queue of the savings bank and the amount of service window as well as the customer's service time.

\section{Analyse}

We obtain the service time as well as service window inside the main levels of the service process and find that they are greatly powerful with the queue quantity. We can look at the queue system from the Table 1 that the queue system of Bank $\mathrm{C}$ is unreasonable. It is due to the data of the first line that the probability of the customers waiting in the queue when arrived system is $94.3 \%$, the average queue time of each customer is 0.4714 hours (28.3 minutes) that is 16 times greater than the average service time of 104 second. But the probability of seven customers is $66.3 \%$ of the system that is unreasonable for the customer. The Bank $\mathrm{C}$ should improve the efficiency to enlarge the service window while facing extremely strong competition. And this should be done if we expand the service window and lessen the service time. Now we will study the two methods as follows that is by expanding the service window, same queue standard and it is like creating customer route. The service rate of every system is 35 persons per hour and the result is shown in the second line of Table 1.

If the second method is adopted by not enlarging the service window, but we can enlarge counting money machine set up management information system of the customers in order to lessen the service time of every business and to build the service quantity ranging from 35 to 60 persons per hour.

The result can be seen in the third line of Table 1 in which the average queue time of each customer lessens the hours from 0.4714 hours to 0.0204 hours, whereas in the average stayed time the hours reduce from 0.5 hours to 0.0371 hours for each customer. The probability of 7 customers in a system reduces greatly from $66.3 \%$ to $1.49 \%$ at the same time. Therefore the outcome in the improvement of system and reducing service time is more suitable enlarging the service window. The time analysis decreasing the time and create the quantity of customer in system reduces greatly and as the customer quantity

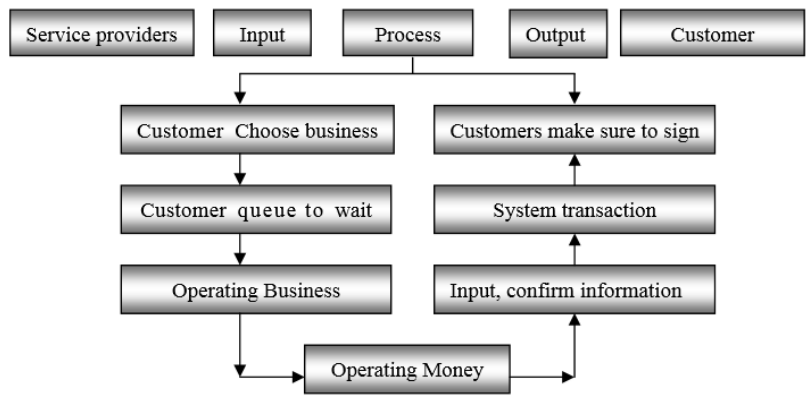

Figure 3: SIPOC of banking system (Source: Wang et al. [11]). increases from 35 to 60 persons, therefore the probability that at least 7 customers in a system decreases to $1.49 \%$.

\section{Improve}

Considering the design analysis, we can utilize two techniques so as to decrease service time by enlarging current counter machine and build MIS of the customer. Other actions can be taken at the same time to understand the objective for instance enlarging the service window and delay for the service by queue machine take a lot of benefits of the system resources.

\section{Control}

We create the improved measures that are incorporated in the daily management and then set up the performance analysis standard so as to keep up the improved performance and to get rid of rebound. We can see important performance improvement after applying LSS project through methodical analysis of bank service. The service efficiency and the bank competitiveness has been increased. Therefore, we finished project of LSS and continuously seeking for a new project.

How to make it constant effectively improved? We should first define a key performance index (KPI) in order to make it a regulating point by keeping in mind the requirements of the banks. The LSS project is operated again if any problem arises each time and do not meet the needs of KPI.

\section{Conclusion}

The improvement of process in commercial banks is a strong, continual advancing process. As a fully developed international banking model, PBS is a strong management model for Pakistan to create an advance commercial bank. In order to realize PBS efficaciously, the systematic perspective in strategic level as well as an efficient operation way in the execution level is required. CPI is a verified approach that has been adopted strongly in all kinds of management processes to manage the high speed changes in the global environment. For the sake of realising PBS, the commercial banks of Pakistan require CPI to adapt to the existing financial deepening and the trend on international level in order to enlarge their core competitiveness. LSS has been extensively used and built in all kinds of management processes as an important tool. The banking sector fixes huge importance to the processes. PBS is an organizational oriented process as an initiative in the management. Therefore LSS technique would be a powerful support to create PBS. The existing conditions and issues of the commercial banks in Pakistan based on the research have created a theoretical model of process advancement: the hybrid deployment model named CPIPBS, and implemented LSS as an important tool to create a dynamic optimization system process. Then it did a conceptual verification of this methodology at the same time. We can achieve great experience and show its effectiveness and approval by the case of bank C, but for the present time to build an implication for this type of study.

\begin{tabular}{|c|c|c|c|c|}
\hline \multirow[t]{2}{*}{ Project } & \multirow[t]{2}{*}{ Symbolised by } & \multicolumn{2}{|c|}{ Before improvement } & \multirow[t]{2}{*}{ After improvement } \\
\hline & & 4 windows & 5 windows & \\
\hline Probability of no customer & $\mathrm{P}_{0}$ & 0.06 & 0.23 & 0.45 \\
\hline Average number of queued customer & $\mathrm{L}_{\mathrm{q}}$ & 15.56 & 2.60 & 0.67 \\
\hline Average number of customers in system & $\mathrm{L}_{\mathrm{s}}$ & 16.5 & 2.80 & 1.22 \\
\hline Average queue time for each customer & $\mathrm{W}_{\mathrm{q}}$ & 0.47 & 0.10 & 0.02 \\
\hline Average waited time for each customer & $\mathrm{W}_{\mathrm{s}}$ & 0.50 & 0.13 & 0.04 \\
\hline Probability of customers prior to queue & $P_{w}$ & 0.94 & 0.77 & 0.55 \\
\hline Probability of at least 7 customer in system & $\mathrm{P}_{\mathrm{s}}$ & 0.66 & 0.16 & 0.02 \\
\hline
\end{tabular}

Table 1: Service comparison before and after improvement. 
Citation: Saeed MS, Nasar A (2016) Continuous Process Improvement (CPI) in Pakistani Banking Sector for Improving Overall Performance. J Bus Fin Aff 5: 210. doi: 10.4172/2167-0234.1000210

The research reaches to the conclusions through the study as follows: 1. the implementation of CPI theory has a great impact to service industries in fact it should consider the effectiveness and efficiency. 2. PBS is an excellent management model for Pakistan to create a modern commercial bank. 3. The associated technique and ideology of CPI with the BPS can acquire the best teamwork management effect. 4. LSS is a powerful operational method to build dynamic optimization system of PBS. 5. To realize that PB, LSS was not enough. It should combine the idea, model system of CPI with the technique and model of LSS. The research proposed a process improvement model through careful analysis and research that is adjustable to the commercial banks of Pakistan and pick out the problems and preventives of implementation of CPI to management banks.

\section{References}

1. Sicilia JD (2008) Department of Defense Lean Six Sigma Deployment Department of Defense pp: 1-21.

2. Plenert G (2011) Strategic Continuous Process Improvement. McGraw Hill Professional.

3. Vance DE (2009) Reengineering, Process Mapping, Continuous process Improvement and Outstanding. Corporate Restructuring pp: 151-167.

4. Protzman C, Whiton F, Kerpchar J, Lewandowski C, Stenberg S, et al. (2016) The Lean Practitioner's Field Book: Proven, Practical, Profitable and Powerful Techniques for Making Lean Really Work. CRC Press.

5. Anand G, Ward PT, Tatikonda MV, Schiling DA (2009) Dynamic capabilities through continuous improvement infrastructure. Journal of Operations Management 27: 444-461.

6. Bookman L, Troy R, McCaffrey M, Randolph G (2010) Using qualityimprovement methods to reduce variation in surfactant administration. Quality Safety Health Care 19: e23.

7. Kreitner R (2008) Principles of Management. (11thedn) Cengage Learning

8. Han KH, Park JW, Jo YH (2008) Process-Centered Knowledge Model for Continuous Process Improvement. Proceedings of the 2008 IEEE IEEM pp: 42-46.

9. Malheiros V, Paim FR, Mendonca M (2008) Continuous Process Improvement at a Large Software Organization. Software Process Improvement and Practice 14: 65-83.

10. Wilson SB, Dobson MS (2008) Goal Setting: How to Create an Action Plan and Achieve Your Goals. (2ndedn) AMACOM Div American Management Association

11. Wang L, Herve DBG, Shen $Y$ (2012) Continuous Process Improvement in Banking Sector and a Model Design for Performance Enhancement. International Journal of Business and Management 7: 130-141.

12. Knapp KJ (2009) Cyber Security and Global Information Assurance: Threa Analysis and Response Solutions: Threat Analysis and Response Solutions. IGI Global.

13. Davenport TH (2013) Process Innovation: Reengineering Work through Information Technology. Harvard Business Press.

14. Linnean III HW (2007) AFO21: Identifying potential failure points in sustaining continuous process improvement across the air force. Alabama: Air command and staff college, Air University.

15. Küng $P$, Hagen $C$ (2007) The fruits of Business Process Management: an experience report from a Swiss bank. Business Process Management Journal 13: $477-487$

16. Snee RD (2010) Lean Six Sigma - getting better all the time. International Journal of Lean Six Sigma, 1: 09-29.

17. Narula V, Grover S (2015) Six Sigma: Literature Review and Implications for Future Research. International Journal of Industrial Engineering and Production Research 26: 13-26.

18. Furterer SL (2016) Lean Six Sigma in Service: Applications and Case Studies. CRC Press.

19. Debela T, Hagos A (2011) The Design and Implementation of Business Process Reengineering in the Ethiopian Public Sector: An Assessment of Four Organizations. African Books Collective.

20. Hayler R, Nichols M (2007) Six Sigma for Financial Services: How Leading Companies Are Driving results with Lean, Six Sigma and Process Management. The McGraw-Hill Companies.

21. Agustiady T (2013) Communication for Continuous Improvement Projects CRC Press.

22. Hines P, Rich N (1997) The seven value stream mapping tools. Int J Oper Prod Man 17: 46-60

23. Kofman F, Repenning N, Sterman J (1994) Unanticipated side effects of a successful quality programs: exploring a paradox of organizational improvement. Alfred P. Sloan School of Management pp: 1-45.

24. Klein KJ, Sorra JS (1996) The challenge of innovation implementation. Academy of Management Review 21: 1055-1080. 